\title{
Audiological Profile in Laurencemoon Biedl Syndrome: A Case Study
}

\author{
Tulsi Sao and Attuluri Navya* \\ NSCB Medical College, India \\ Submission: April 13, 2017; Published: April 21, 2017 \\ *Corresponding author: Attuluri Navya, AIISH, Mysore, India, Tel: 9036377964; Email: navyaaslp@gmail.com
}

Abbreviations: LMB: Laurence-Moon Biedl; BBS: Bardet-Biedl Syndrome; OAE: Otoacoustic Emissions; PTA: Pure Tone Audiometry; ABR: Auditory Brainstem Response; TEOAE: Transient Evoked Otoacoustic Emission; DPOAE: Distortion Product Otoacoustic Emission; URT: Upper Respiratory Tract; ART: Acoustic Reflex Threshold

\section{Introduction}

Laurence-Moon Biedl (LMB) syndrome is an autosomal recessive genetic disorder, characterized by structural and functional abnormalities of organs [1]. This syndrome was first described by Laurence and Moon in 1866 [2]. This syndrome is also called Bardet-Biedl syndrome (BBS) as Bardet and Biedl added additional polydactyly feature [3]. The estimated incidence is 1:160,000 in northern European populations and $1: 13,500$ in some Arab populations as reported [3]. The sex ratio of LMB syndrome is 1.3:1[4]. This syndrome share many clinical features but mainly characterized by varying degrees of hearing impairment, mental retardation, obesity, retinitis pigmentosa, extra digits on the hands and feet [2,5]. Previous literature reported that LMB syndrome may have normal hearing sensitivity, conductive hearing loss or sensorineural hearing loss [6].

However, conductive hearing loss (otitis media) more frequent in this cases which resolved by puberty and sensorineural hearing loss in less frequent [4]. The mild to moderate conductive component may be attributable to chronic otitis media has been reported in studies [4] but symmetry and magnitude of sensorineural hearing loss was unexplained. Thus in this study, all administrated objective test batteries will give valuable information regarding symmetry and severity of hearing loss. There is scarce of research studies highlighting the audiological findings in Laurence-Moon Biedl (LMB) syndrome which limits our understanding of hearing disorders in this population. Hence the current study aimed at profiling the audiological findings in a patient with LMB syndrome by using state of art technological instruments for better understanding which aids in channelizing to accurate diagnosis.

\section{Case Report}

\section{Case History}

A18 year old young male hospitalized due to obesity and retinitis pigmentosa. He is the elder son of the family with three younger brothers and a sister. There was no family history of hereditary diseases and hearing loss. As a part of detail health check up, he underwent various routine evaluations including, ophthalmological, psychological, radiological, audiological, speech and language evaluation, and laboratory tests. Ophthalmological evaluation revealed retinitis pigmentosa (night blindness and blurred vision) in both eyes. Psychological evaluation shows mild to moderate mental retardation. Radiological evaluation i.e. MRI (magnetic resonance imaging) reports of the brain indicated no structural abnormalities. Laboratory test showed Thyroid profile within normal limits, blood sugar level was $114 \mathrm{mg} / \mathrm{dL}$, Hb was $10.7 \mathrm{gm}$, FSH level was $4.01 \mathrm{mIV} / \mathrm{m}$, LH was $1.59 \mathrm{mIV} / \mathrm{m}$, prolactin hormonal level was $4.8 \mathrm{mg} / \mathrm{ml}$ and testosterone level was $34.5 \mathrm{mg} / \mathrm{ml}$.

Speech and language evaluation indicated deficient speech and language abilities with history of delayed speech and language milestones. His speech was characterized by hypernasality and misarticulation. Followed by the evaluations he was diagnosed as Laurence-MoonBiedl syndrome. The various typical features of syndrome i.e. retinitis pigmentosa,obesity including polydactyl (extra finger on hand) and mental retardation were evident in the patient. During audiological evaluation, complain of cold with no history of ear pain, ear discharge, blocking sensation, vertigo, nystagmus, nausea and previous history of ear surgery. The detail audiological evaluations included otoscopic examination, pure tone audiometry (PTA), immittance 
audiometry, otoacoustic emissions (OAE), auditory brainstem response (ABR). The instruments used and the procedure followed were explained in the method section.

\section{Methods \& Materials}

\section{Otoscopic examination}

Otoscopic examination was performed using otoscope (Mini 3000 HEINE) for evaluating the status of ear canal and tympanic membrane.

\section{Pure tone Audiometry}

Calibrated single channel Audiometer (ALPS AD 2000+) was used.TDH-39 supra-aural earphone housed in MX 41/AR cushions were used for air-conduction and Radioear B-71 bone vibrator was used for bone conduction test. Pure tone threshold were obtained using modified Hughson and Westlake procedure at octave frequencies from $250 \mathrm{~Hz}$ to $8000 \mathrm{~Hz}$ for air conduction and $250 \mathrm{~Hz}$ to $4000 \mathrm{~Hz}$ for bone conduction testing.

\section{Immittance Evaluation}

Calibrated Maico Easy tymp was used for Immittance Evaluation. Tympanometry was performed bilaterally using $226 \mathrm{~Hz}$ probe tone. Acoustic reflex thresholds were measured at octave frequencies from $250 \mathrm{~Hz}, 500 \mathrm{~Hz}, 1000 \mathrm{~Hz}, 2000 \mathrm{Hzand}$ $4000 \mathrm{~Hz}$ ipsilateral and contralateral in both ears. The repeated testing was done for to test the reliability of results.

\section{Otoacoustic Emission}

TEOAE (Transient Evoked Otoacoustic Emission) and Distortion product Otoacoustic emission (DPOAE) were performed in both ears. Transient evoked Otoacoustic emission was measured using non-linear click at $80 \mathrm{~dB}$ Peak SPL to estimate amplitude responses. A suitable probe with appropriate probe tip was used. A total of 260 click stimuli were presented and the responses were averaged. Reproducibility of more than $50 \%$ and an SNR of $3 \mathrm{~dB}$ or above was considered as a response. Overall TEOAE amplitude response and signal to noise ratio at 1000, 1500, 2000, 3000 and $4000 \mathrm{~Hz}$ were noted. DPOAE were performed in setting of frequency band from $1000 \mathrm{~Hz}$ to $6000 \mathrm{~Hz}$, stimulus intensity L1=65dBSPL \& L2 $=55 \mathrm{dBSPL}$, frequency ratio F2:F1=1.2:1 and signal to noise ratio of at least $6 \mathrm{~dB}$ with a reproducibility score of at least $70 \%$.

\section{ABR (Auditory brainstem response)}

Biologic Natus pro (ver 7.2.1) instrument was used. Clickevoked ABR was performed in both ears monaurally. The testing was performed while patient was sleeping. Single channel recording was used in which non-inverting electrode was placed on the Upper forehead (Fz); the inverting electrode was placed on mastoid of test ear and ground electrode was placed on mastoid of non test ear. Electrode impedances were less than $5 \mathrm{k} \Omega$, and inter-electrode impedances were less than $2 \mathrm{k} \Omega$. Eartone-3A insert earphone was used to present the stimuli. At least 1500 click stimuli in rarefaction polarity presented at 30.1 click/sec repetition rate. Potentials were recorded in band-pass filter setting $100 \mathrm{~Hz}-3000 \mathrm{~Hz}$ with an amplification factor of 1 , 00,000. Recordings were started from $70 \mathrm{dBnHL}$ and lowering intensity at $10 \mathrm{~dB}$ step while ensuring the replicability of the waveform at each intensity level.ABR waveforms were analyzed at $10 \mathrm{~ms}$ time window setting. All testing were performed in sound treated room in which ambient noise levels well within the permissible limits as per ANSI S3.1, 1991 standards [7].

\section{Results}

\section{Otoscopic examination}

Otoscopic examination findings show ear canal clean and tympanic membrane intact in both ears.

\section{Puretone audiometry}

The puretone audiometry was not completed as the client was giving inconsistent response during puretone audiometry.

\section{Immittance Audiometry}

Immittance findings revealed "C" type tympanogram in left ear and "A" type tympanogram in Right ear with absent of ipsi and contralateral reflex in both ears (Figure 1) (Table 1).

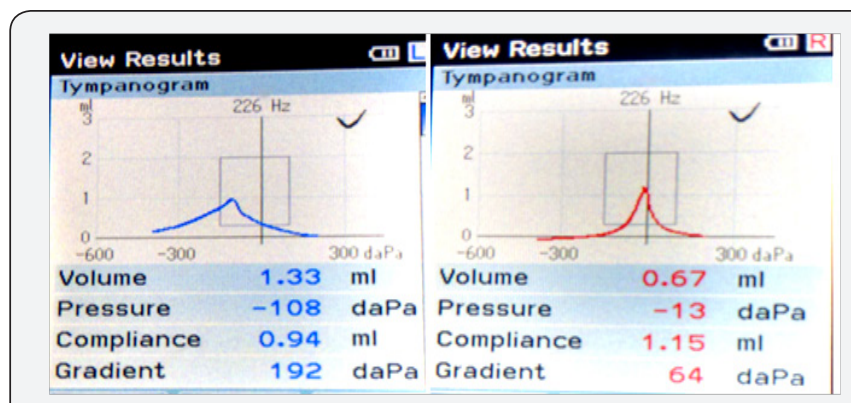

Figure 1: Indicated tympanogram for left ear $(L)$ and right ear (R).

Table 1: Indicated value of Tympanometric parameters of both ears.

\begin{tabular}{|c|c|c|c|c|}
\hline & $\begin{array}{c}\text { Ear canal } \\
\text { Volume }\end{array}$ & $\begin{array}{c}\text { Peak } \\
\text { pressure }\end{array}$ & Compliance & Gradient \\
\hline Right Ear & $0.67 \mathrm{ml}$ & $-13 \mathrm{dapa}$ & $1.15 \mathrm{ml}$ & $64 \mathrm{dapa}$ \\
\hline Left Ear & $1.33 \mathrm{ml}$ & $-108 \mathrm{dapa}$ & $0.94 \mathrm{ml}$ & $192 \mathrm{dapa}$ \\
\hline
\end{tabular}

\section{Otoacoustic Emission}

Transient evoked otoacoustic emission absent in both ears. However Distortion product otoacoustic emission (DPOAE) was pass in both ears (Figures $2 \& 3$ ). Note: In Figure 2 \& Figure $3 \mathrm{CH}$ indicate channel, L indicate for left ear, R indicate for Right ear, DP indicate distortion product, NF indicate noise floor, P indicate Pass and dBSPL indicate decibel sound pressure level (Table 2). 


\section{Global Journal of Otolaryngology}

\section{Auditory Brainstem Response}

Table 2: Indicate the frequency specific otoacoustic emission results.

\begin{tabular}{|c|c|c|c|c|c|c|c|}
\hline \multirow{7}{*}{ Left Ear } & F1 & F2 & DP frequency & DP & NF & $D P / N F(d B)$ & Pass/Refer \\
\hline & 844 & 984 & 703 & 13.8 & -16.8 & 30.7 & Pass \\
\hline & 1688 & 2016 & 1359 & 13.7 & -15.4 & 29.1 & Pass \\
\hline & 2484 & 3000 & 1969 & 14.2 & -23.6 & 37.8 & Pass \\
\hline & 3328 & 3984 & 2672 & 14.9 & -18 & 32.8 & Pass \\
\hline & 4172 & 5016 & 3328 & 16.5 & -16.8 & 33.4 & Pass \\
\hline & 5016 & 6000 & 4031 & 8.4 & -12 & 20.4 & Pass \\
\hline \multirow{6}{*}{ Right Ear } & 844 & 984 & 703 & 13.8 & -10.4 & 24.2 & Pass \\
\hline & 1688 & 2016 & 1359 & 12.3 & -14.7 & 27 & Pass \\
\hline & 2484 & 3000 & 1969 & 14 & -23.1 & 37.1 & Pass \\
\hline & 3328 & 3984 & 2672 & 15 & -16.9 & 31.9 & Pass \\
\hline & 4172 & 5016 & 3328 & 17.2 & -16.4 & 33.6 & Pass \\
\hline & 5016 & 6000 & 4031 & 11.5 & -14.7 & 26.2 & Pass \\
\hline
\end{tabular}

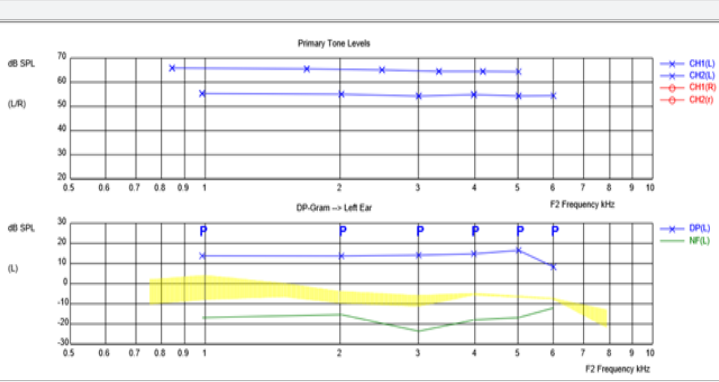

Figure 2: Otoacoustic emission findings for left ear (L).

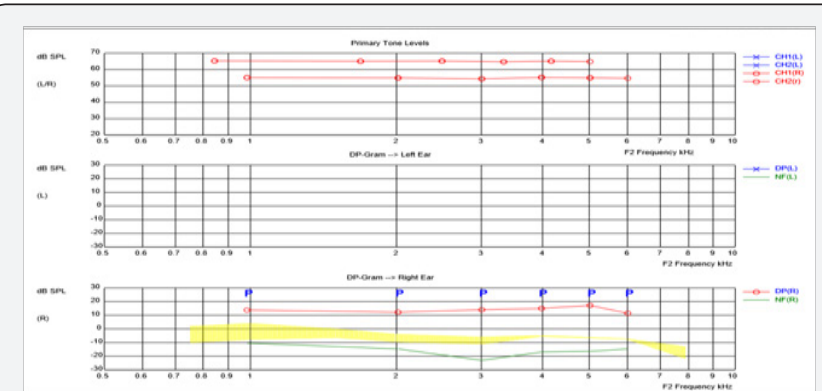

Figure 3: Otoacoustic emission findings for Right ear (R).

ABR result show Vth peak obtained at $50 \mathrm{dBnHL}$ in both ears indicative of bilateral mild hearing loss (Figure 4) (Table 3).

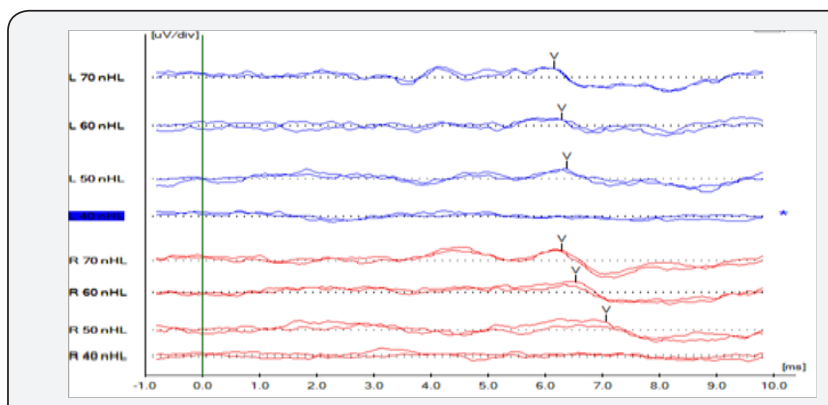

Figure 4: Auditory brainstem response result for left ear (Blue) and Right ear (Red).
Table 3: Indicate Latency of Vth peak at different intensity level.

\begin{tabular}{|c|c|c|c|}
\hline & Intensity & $\begin{array}{c}\text { Absolute latency } \\
\text { for Left Ear }\end{array}$ & $\begin{array}{c}\text { Absolute latency for } \\
\text { Right Ear }\end{array}$ \\
\hline 1. & $70 \mathrm{dBnHL}$ & $6.15 \mathrm{~ms}$ & $6.28 \mathrm{~ms}$ \\
\hline 2. & $60 \mathrm{dBnHL}$ & $6.28 \mathrm{~ms}$ & $6.53 \mathrm{~ms}$ \\
\hline 3. & $50 \mathrm{dBnHL}$ & $6.3 \mathrm{~ms}$ & $7.07 \mathrm{~ms}$ \\
\hline
\end{tabular}

\section{Discussion}

The present study outlines the audiological test outcomes in Laurence-moon Biedl syndrome. The results of the visual examination through otoscope indicated no structural abnormalities of ear canal and tympanic membrane. Followed by otoscopic examination the patient was subjected to pure tone audiometry to evaluate hearing thresholds. Puretone audiometry is subjective test used to detect the hearing sensitivity from 250 to $8000 \mathrm{~Hz}$ [8]. The PTA results were inconsistent as the patient failed to provide consistent response to presented stimulus. The reduced ability to comprehend the instructions for responding to stimulus could be due to patient's limited cognitive abilities. Several studies also concluded that LMB syndrome have impaired cognitive ability [4]. Literature shows that pure tone findings may vary from normal hearing to moderate conductive hearing loss [6]. However, the reliability of these findings in some patients is questionable in the presence of border line retardation. Previous study reported unreliable hearing thresholds based on pure tone audiometry in patients with mental retardation [9].

To overcome the limitations of the evaluations based on subjective responses i.e., PTA, objective assessment of hearing procedures were adapted [10]. In current study, immittance audiometry, otoacoustic emission, and auditory brainstem response were used to evaluate the hearing based on objective measures. Immittance Audiometry was used to detect the admittance of ear. Immittance evaluation includes tympanometry and Reflexometry [11]. Tympanometry used to detect movement of tympanic membrane and middle ear functioning. and 
reflexometry measures the contraction of stapedius muscle at higher intensity level [11]. The results indicated compliance and ear canal volume are within normal range for both ears reflecting the adequate mobility of tympanic membrane and no perforation of TM or presence of impacted wax. However, slight deviation in the middle ear pressure towards negative values was noticed in left ear as a result of upper respiratory tract (URT) infection. Thus, the overall findings suggestive of no abnormalities in the middle ear structures but, there is increased negative pressure indicating acute stage of eustachian tube dysfunction due to URT in left ear.

Reflexometry test result indicated absent of acoustic reflex threshold (ART) at all frequency in both ears. It may be due to sensorineural pathology. In support of this findings [8] reported that acoustic reflex threshold can be absent sensorineural hearing loss. Similar findings were documented by [4] in which reported the presence of conductive hearing loss (otitis media) during early childhood in patients with LMB syndrome which may get resolved by puberty. Otoacoustic emission test were administered to detect outer hair cell function as emission generated from cochlea [12]. TEOAEs are more sensitive to cochlear pathology than DPOAE as studies reported that TEOAE are absent if hearing threshold exceeds 20-30dBHL [12]. DPOAE can be elicited even in moderate hearing loss patients where TEOAE are absent [12]. Thus, in the current study, TEOAE are absent and DPOAE are present in both ears. This implies that the patient with LMB syndrome is having mild to moderate degree hearing loss. The absence of TEOAE is due to their high sensitivity and gets nullified even in the presence of mild noise levels.

ABR testing is performed for threshold estimation [13]. It is also used to check the reliability of hearing thresholds by comparing with pure tone behavior threshold. In this patient, ABR results indicated Vth peak with click stimulus presentation at the level of $50 \mathrm{dBnHL}$ but no Vth Peak was obtained at $40 \mathrm{dBnHL}$. Studies reported that the ABR threshold is $20 \mathrm{~dB}$ less sensitive than pure-tone behavioral thresholds [14].Thus, in the current study the patient is having bilateral mild hearing loss. Latencyintensity function is used to differentially diagnosis conductive hearing loss and sensorineural pathology. Studies reported that an increase in absolute latency of $0.3 \mathrm{msec}$ as intensity decreases by $10 \mathrm{dBis}$ observed in individuals with normal hearing and cochlear pathologies [15]. The Vth peak latency will fall within normal limits but may be slightly prolonged at near threshold intensity in cochlear pathology, where as Vth peak latency gets significantly prolonged at all intensity levels in conductive hearing loss [15].

The result of ABR findings in the current study indicates an increase in absolute latency of around 0.02 to $0.25 \mathrm{~ms}$ with every $10 \mathrm{~dB}$ reduction in intensity at suprathreshold level. Only at threshold level for right ear inter intensity latency difference is $0.54 \mathrm{~ms}$. The increase in intensity latency function near the threshold level is prolonged due to more time required to activate auditory nerve at lower intensity level than higher intensity level. Thus, temporal coding affected in cochlear pathology due to broadening of auditory filter. However, inter-peak latency could not identify as poor waveform morphology. It may be due to poor neural synchronization. These co-relative threshold estimation \& latency intensity function ABR findings suggestive of patient with LMB syndrome have cochlear pathology. Previous literature reported that some LMB syndrome has sensorineural hearing loss [16,17].

\section{Conclusion}

The present study focused on profiling the audiological findings in a patient with LMB syndrome. The audiological evaluation indicated bilateral mild hearing loss including the involvement of sensorineural and conductive pathology. As patients with LMB syndrome do exhibit various delineating symptoms related to mental retardation, obesity, retinitis pigmentosa, extra digits on the hands and feet, the health care professionals tend to ignore issues related to hearing loss as it is invisible. The development of speech and language abilities, learning and communication skills may get severely hampered in the presence of hearing impairment. No drug therapy exits for sensorineural hearing loss but early identification and intervention can facilitate development of communication. Finally, it is important to remember the genetic nature of LMB syndrome and its effect on hearing. Although the present study was done only in one child of the family but similar condition might be occur among siblings. Thus the present study also highlights the importance of prenatal genetic counseling for all pregnant mothers. Furthermore the present study increased awareness of the condition which may lead to involvement of audiologist in the diagnosis as early as possible and providing immediate management. Educational planning should take the prospect of future hearing loss into consideration.

\section{References}

1. Qureshi T, Ayub, Nasti AR, Ashai M (2003) Laurance-Moon (Bardet) Biedl Syndrome. JK-Practitioner 10 (3): 217-218.

2. Levy M, Lotem M, Fried A (1970) The Laurence-Moon-Biedl-Bardet syndrome. J Bone Joint 52(2): 318-324.

3. Forsyth E, Beales PL (2013) Bardet-Biedl syndrome. Eur J Hum Genet 21(1): 8-13.

4. Beales PL, Elcioglu N, Woolf AS, Parker D, Flinter FA (1999) New criteria for improved diagnosis of Bardet-Biedl syndrome: results of a population survey. J Med Genet 36(6): 437-446.

5. Mehra KS, Gupta RB, Dayal Y (1961) Laurence-Moon-Biedl Syndrome. Br J Ophthalmol 46(1): 56-57.

6. Frazier JR, Frazier DM (1974) Exceptional children: Biological and psychological perspectives. MSS Information, New York, USA.

7. American National Standards Institute (ANSI) (1999) Maximum permissible ambient noise levels for audiometric test rooms. ANSI, New York, USA, S3: 1-1999. 
8. Gelfand SA (2001) Essentials of audiology. Thieme, New York, USA.

9. Lloyd LL (1970) Audiological aspects of mental retardation. Int Rev Res Ment Retard 4: 311-374.

10. Hall JW, Swanepoel DW (2010) Objective assessment of hearing. Plural Pub, San Diego, CA, USA.

11. Martin FN, Armstrong TW, Champlin CA (1994) A survey of audiological practices in the United States. Am J Audiol 3(2): 20-26.

12. Kemp DT (2002) Otoacoustic emissions, their origin in cochlear function, and use. Brit Med Bull 63(1): 223-241.

13. Jerger J (1978) Prediction of sensorineural hearing level from the brain stem evoked response. Arch Otolaryngol 104(8): 456-461.
14. Stapells DR (2000) Threshold estimation by the tone-evoked auditory brainstem response: A literature meta-analysis. J Speech-Lang Path \& Audiology 24: 74-83.

15. Colon E, Visser SL (1990) Evoked potential manual: A practical guide to clinical applications. Kluwer Academic, Dordrecht, Netherlands, Europe.

16. Northern JL, Downs MP (2002) Hearing in children. Lippincott Williams \& Wilkins, Philadelphia, PA, USA.

17. Ross AJ, May-Simera H, Eichers ER, Kai M, Hill J, et al. (2005) Disruption of Bardet-Biedl syndrome ciliary proteins perturbs planar cell polarity in vertebrates. Nat Genet 37(10): 1135-1140.

\section{Your next submission with Juniper Publishers will reach you the below assets}

- Quality Editorial service

- Swift Peer Review

- Reprints availability

- E-prints Service

- Manuscript Podcast for convenient understanding

- Global attainment for your research

- Manuscript accessibility in different formats

( Pdf, E-pub, Full Text, Audio)

- Unceasing customer service

Track the below URL for one-step submission https://juniperpublishers.com/online-submission.php 